\title{
The Cass' Theory of Sexual Identity Formation: A Study of the Complexities of Queer Identity Development
}

\author{
Fraylanie A. Aglipay \\ University of San Francisco, San Francisco, USA
}

\begin{abstract}
This research will examine the Cass' Model of Sexual Orientation Formation, and it will be supported by Cameron's experiences of coming out during, before, and after his undergraduate college years. This paper will be answering questions in regards to the validity of the six stages of development, the congruency of Cameron's experiences to each of these stages, and the accuracy of Stage 6: Identity Synthesis as the end point stage for identity development. In addition, this paper will investigate whether one's sexual development follows a linear progression or multiple developmental trajectories. Hence, this paper will explain the three interviews conducted. As a conclusion, the paper will justify that sexual identity formation is unique and different for every individuals and it does not follow a linear progression. Additionally, the six stages of development are considered as a framework for self-identification, and that end point development is not limited to Stage 6: Identity Synthesis. Lastly, it will briefly include the importance of the study to student affairs practitioners.
\end{abstract}

Keywords: sexual orientation identity formation, identity confusion, identity comparison, identity tolerance, identity acceptance, identity pride, identity synthesis

\section{Introduction}

The opportunity to attend college is a gift for oneself. It does not only nourish one's knowledge, but it is also an avenue for personal growth. Cameron, who lives in a town Northeast of Los Angeles, sees college as an opportunity to explore his identity and to recreate a new self without any restriction. School for him becomes an access to self-validation and community networking, which he considers essential to his development. Growing up, he has always been conscious about things that are happening around him. His family provides a space for him to question and to access answers at an early age. He openly challenges his family when it comes to the LGBTQ (lesbian, gay, bisexual, transgender, and queer) related issues. For him, these issues have always triggered his curiosity, but he never fully understands how it relates to him.

When he transitioned to college, he purposely moved to Los Angeles because it was completely different from where he grew up. He wanted to move to a city where he can embody the identity that was new and nonconforming, yet he felt strongly attached to. His coming out experiences with his family and friends contributed to the search for a better understanding of his sexual identity in college. Before he started his college career, he already envision himself to exploring in depth the complexities and uncertainties of his sexual identity. The numerous workshops, events, and programs that he facilitated and collaborated with other organization initiated awareness and discussion on campus at the same time nourishing his curiosity. As a result,

Fraylanie A. Aglipay, graduate student, School of Education, University of San Francisco. 
he started networking and forming a support group where he was able to challenge various issues in regards to his identity. The layers of growth and the developmental process of reaching to his identity present the stages of sexual identity development. It was interesting how these developments were most evident in college. Multiple studies were done to predict development and pattern among individuals in regards to their orientation. In the Cass Model of Sexual Orientation Identity Formation, the researcher accounted sequential stages describing identity formation. It is believed that individuals go through identity searching following these stages in a sequential order. Thus, one does not necessarily go through all the stages. One might stay in a specific stage and not progress, others may reach a certain stage but progress backwards, and some may go through all the stages and achieve the optimum level of identity formation. However, a number of factors may play a significant role in influencing one's identity development. First is the changing definition of gender identity through context and time. What may be relevant in the past may no longer appropriate in the present time. Secondly, the current LGBTQ coming out issues may no longer be applicable due to the various resources available and increasing number of support from the community. Third, diverse experiences and background may weigh equally important and influential in one's everyday choices and decisions. Therefore, this paper aims to discuss the different stages in relation to Cameron's experiences. To seek validity of the multi-stage process and how it applies to Cameron's experiences and whether one must undergo the sequential order of stages in order to fully reach the identity synthesis. Lastly, to determine whether there is potential growth even after one reaches identity synthesis.

\section{The Cass Model of Sexual Orientation Identity Formation}

The community has multiple perspectives in regards to the LGBTQ identities. Most of the time, sexual orientation is link to a mental disorder. Researchers study the complexities of LGBTQ identities to find the meaning of experiences relating to the one's sexual identity. Dr. Vivienne Cass is one of the many researchers who studies the gay and lesbian identity development and how these experiences fit a framed stage. There are six stages that describe the movement of a person's identity discovery. These stages are created to solidify an understanding the identity development at the same time facilitate a better conversations and services for individuals who are faced with every day struggle to identifying their sexual orientation. Thus, "Cass identified six stages of perception and behavior, moving from minimal awareness and acceptance of a gay or lesbian identity to a final stage in which gay or lesbian identity is integrated with other aspect of the self" (Evans, Forney, Guido, Patton, \& Renn, 2010). Hence, this linear stage model examines development and promoting healthy growth for LGBTQ individuals.

\section{Methodology}

The research goes through three series of interviews. Each of these interviews is done outside the classroom. Thus, there are established rules of engagement before every interview is conducted. The first interview is designed to create a general framework of Cameron's experiences specifically in college. The second interview is in response to the repeating themes from the first interview. During the first interview, he mentions about his relationships with his family and mentors. He narrates stories of his involvement on campus and how those experiences mold the person he is now. Though he identifies himself as Queer, his coming out process is not frequently mentioned during the interview. There is an unclear connection between his identity and the process that he goes through in relation to the person that he is before and now. The second interview 
focuses on how the Cass Model of Sexual Orientation Identity Formation can be related to Cameron's coming out process. The questions asked are specifically about his coming process and the different factors that contribute to this process. His progression of embracing his identity reflects stages that the model defines. However, the model strongly detailed a linear progression within these stages. As a result, the third interview needs to be conducted. The questions ask in this interview are formulated according to the definition of each of the stages. These questions are also asked sequentially to determine if Cameron's coming process follows a linear progression.

\section{Assessment of the Validity of the Six Stages of Model of Identity Development}

The six stages of sexual development include identity confusion, identity comparison, identity tolerance, identity acceptance, identity pride, and identity synthesis. The prestage is an addition to model to where it encompasses a preconceived notion of curiosity and questioning of identity. The following stages will be examined through the lens Cameron's coming out experiences and interpret it using the general description of each of the stages mentioned in the model.

\section{Prestage}

The recognition that one should identity himself or herself as heterosexual becomes society taught people to identify as one is characterized in this stage. Cameron speaks about teachings what a male or female should be in the bible. He does not argue about it because for his mom is also instilling this belief since he was a child. For him, it is more of an obligation to fulfill his duties as a son and member of the church.

\section{Stage 1: Identity Confusion}

Individuals experience awareness of one's difference in sexuality towards the gender mainstream. There is a realization that one's behavior or feelings are different from the society's definition of gender (Evans et al., 2010). Cameron demonstrates characteristics that this stage defines. He sees himself as non-straight and not confirming to the society's expectation towards the male gender. Cameron explains:

I can say I do remember the strong feelings I had during my late teenage years, like age 16/17. At first I didn't understand it, really, I was scared that I would be disowned or shunned if my family found out. (Personal Communication, November 28, 2012)

The cass model explains factor of self-alienation, acceptance, curiosity, and questioning as part of the process for this stage (Evans et al., 2010). Evidently, one's identification causes emotional distress that can contribute to one's processing of identity. Cameron shows initial markers that this stage highlights. He is fearful and confuse about emotions that are not complying with the society.

\section{Stage 2: Identity Comparison}

The awareness and questioning of one's homosexual identity during Stage 1 is further explored in this stage. As an individual increasingly realizes that one's feelings and behaviors are different from others, one realizes consequences of admitting to people. The two polarizing reactions, negative and positive, determine the willingness of an individual to address his or her feelings to others. For some people, they choose to accept and embody their difference among others. Others may reject such feelings and behaviors and tries to recreate their identity to accommodate to the society's description of what is the acceptable gender role. Cameron shares his reservation on opening up his other identity to his peers and family. He said, "And because I am from a 
small town I was soooo nervous and cautious. I had to make sure my alter-profiles were private, different names, age..blah blah.. almost like another identity" (Personal Communication, November 28, 2012). The nervous feeling of Cameron shows a sense of discomfort on the idea that by him coming out to the people around him may result to social alienation. His location is also a determinant of how he projects himself in public. For him, the city that he grows up holds conditions that are not favoring some of his beliefs and opinions most especially the idea of being gay. Thus, with the conditions set by the environment and the society, he is slowly and maybe tentatively admitting to himself his homosexual identity. In response to Cameron's reactions, he is going through a stage where there is internal self-commitment to homosexual feelings or behavior due to the perception the society. The cass model describes that individuals in this stage often times compare themselves to the heterosexual or straight majority. Hence, the feeling of being different is evident.

\section{Stage 3: Identity Tolerance}

The acknowledgement of one's LGBTQ identity becomes prevalent in this stage (Evans et al., 2010). This stage includes support from individuals with similar identity. There is a need for relating oneself to the LGBTQ community to find validity of feelings and behaviors. According to Degges-White, Rice, and Myers (2000), "If one sees ones homosexual self-image as undesirable, a positive contact in this stage can lead to a reevaluation of the negative perception. If the experience is a negative one, it increases one's negative self-conception" (Overview of the Cass' Theory, para. 4). In regards to Cameron's experience, even if he grows up in a family where issues on LGBTQ are discussed, he still feels hesitant in admitting his sexuality to his family. Cameron narrated:

At first I didn't understand it, really, I was scared that I would be disowned or shunned if my family found out. But I don't think I felt bad for being not straight. I used social media to find other non-straight guys. I remember using Myspace and chat rooms to just talk to people. (Personal Communication, November 28, 2012)

Most of the time, it is harder to confront family and love ones with issues of sexuality. Reactions receive from family and love ones can be determinants of the success or failure of one's identity progress. With Cameron, religious obligation is one hindrance for him to openly discuss his sexuality with his family.

\footnotetext{
My family is so complex and diverse. A lot of our values are around diversity and acceptance of people lifestyle but there is a lifestyle that is being open to and so I was brought up with an open mind uhm and I think my coming out process is learning about my sexual identity. It expanded my mind more, which gave me the responsibility to extend to my family and my love ones mine. (Cameron, Personal Communication, November 23, 2012)
}

The use of media as an avenue for expression provides him exposure to the LGBTQ community. Myspace and other chat rooms are outlets that do not required him to reveal the totality of himself, but connect him with the identity that he feels needed to explore more. Evidently, there is self-understanding and possibly self-acceptance of one's identity. Individuals might not get the support from the people close them, but they are finding other spaces to express themselves and feel more validated than rejected.

\section{Stage 4: Identity Acceptance}

This stage highlights the importance of increasing awareness of one's identity. An individual finds that the presence of LGBTQ people in his or her life is essential to his or her growth as a person. Thus, learning to accept one self is contributed by the interactions with other LGBTQ individuals. One feels that establishing a 
community among other LGBTQ individuals can lead to a healthier being. A person feels more stable about their sexuality and becoming more committed to embracing his or her LGBTQ identity (Evans et al., 2010). Cameron reaches this stage when he is 19 years old in his sophomore year in college. It is this age that he starts to question the complexities of different labels within the LGBTQ spectrum. His various political standpoints on these labels guide him to fully distinguish his sexuality. He explained:

During this time I began really understanding myself, my attractions, how often I did feel "queer" in sense of 'outside of the norm" and so I embraced Queer. I feel Queer is the closes term that represents my sexuality, and my stance against discrimination and heterosexism. I am a queer male, Black-American man, who's in a same-sex relationship. I know I felt more at ease, and peace once I started to publicly identify as queer. (Cameron, Personal Communication, November 28, 2012)

At first, he is debating between the identity of being bisexual or gay. He thinks that these two labels characterized the label of non-straight, which he identifies himself with in the beginning when he first comes out to his family and friends. People around him are questioning him about his bisexual and gay identity throughout his own process of self-exploration. Cameron says that identifying himself with two labels confuse people, rather than comprehending the complexities the LGBTQ identities. While he slowly understands his own identity, he is also becoming more conscious and responsible on educating the society. This stage entails a person being selective of his or her group within the LGBTQ community. At some point, one is forced to re-interpret and re-learn meanings and ideologies behind the LGBTQ spectrum of identity. One is not only looking for belongingness from family and love ones, but also a feeling of fitting in or accepted in the LGBTQ community.

\section{Stage 5: Identity Pride}

The complete acceptance of one's identity is transparent in this stage. An individual involves himself or herself in progressive actions and activism where LGBTQ issues are given emphasize in his or her search for deeper meanings of one's identity. As follows, there is a strong association with the LGBTQ community. The responses of the community are impactful to one's self-reflection of identity. The individual are aware of issues like prejudice, discrimination, and oppression that are evident in the LGBTQ community. "Feelings of both pride in things gay and anger at things not gay propel individuals into activism and confrontation with an oppressive society" (Evans et al., 2010). Indeed, individuals who reach this stage are becoming more visible in the community. The relationship between the heterosexual and homosexual groups is similar to the point where Cameron was slowly becoming involved in the LGBTQ organization on campus. He briefly listed his involvement on campus:

I planed discussions, marches, workshops, panels all dealing with LGBTQ identity and rights/equity/inclusion. I've marched in many Prop 8 marches. I've coordinated my undergraduate institutions "Queer Weddings". The queer wedding was in response to Prop 8 passing. I created my undergraduate institution first Mentorship Program that focused mentoring LGBTQ/questioning high school students. This Mentorship was in response to the LGBTQ suicides and murders. (Cameron, Personal Communication, November 28, 2012)

His diverse experiences in college give him new perspectives not only in regards to his sexuality, but other issues that concerns around his identity. He uses his personal interest as a platform for him to challenge conservative and traditional ideas. Correspondingly, the pride in one's identity drew attention on his social responsibility for the community. An expression of one self in public demonstrates pride and seeking validity of one's identity that may be seen radical towards the heterosexual group of people. 


\section{Stage 6: Identity Synthesis}

Cameron's sexual identity is no longer his sole identity. This stage emphasizes recognition of multiple identities of a person and the significance of all these identities to one's growth. The cass model states that this is the final stage. A person is seen to be at a comfortable and secure stage of development (Evans et al., 2010). Cameron justified:

I view myself as being queer. And with this identify I feel I have a responsibility of living my life with pride. And pride means being completely happy about how I live my life. And I find it my responsibility as an educator to enhance education institutions, and making sure that other LGBTQ students, no matter if they are in a big city or small rural town; know that they are not alone. (Personal Communication, November 28, 2012)

Cameron processes things differently when he reaches this stage in comparison to when he starts coming out to his family and friends. He shows contentment in the choices he makes and extending himself to the people around him. Indeed, personal goals become one with the role that he plays in the society.

\section{Findings/Outcomes}

The process that Cameron goes through from the day that he decides to come out to his friends and family to the time when he fully embraces his identity shows a parallel development with the cass model. His responses to every stage correspond to the predicted description of the model. Therefore, the results of the interviews authenticate the findings of the cass model. There is definitely movement of progress from the time that he comes out to his family and friends to his present state of mind. He goes through all those stages and has been able to demonstrate growth in each of those stages. Each of the stages that the cass model offers is apparent to Cameron's sexual development. However, it is also evident that Cameron's process of development does not follow a sequential order. There is definitely overlapping stages for Cameron. During Cameron's Stage 4: Identity Acceptance, he is going through his own questioning on what label he wants for people to refer as. At first, he labels himself as bisexual or gay, but the people around him do not really fully grasp the idea of interchangeable labels or what are the meanings behind the labels. Though he is confident about his sexuality, he is still compromising to the society's confusion on the choice of label or identity he presents himself. In a way he is going back to Stage 2: Identity Comparison where he is learning again to be comfortable on the label he chooses and accepts it even with how the society receives it. Likewise, Stage 4: Identity Acceptance can directly move towards Stage 6: Identity Synthesis. A positive experience within the heterosexual group where acceptance is freely given directs a person to Stage 6. Cameron finds mentors that encouraged him, family members that support him, and multiple spaces that acknowledge him and the multiple identities he has. There times in the interview that Stage 4: Identity Acceptance and Stage 5: Identity Pride are seen as interchangeable depending on the situation. Cameron reaches a stage of distinguishing his label and other identities that plays a significant role in his sexual orientation development. Although he knows what label he wants to be identified in public, there is a constant struggle of incorporating his queer identity with other identities. It is evident within his experiences that the other identities, like race and culture, affect greatly his transition from one stage to another. Cameron narrates, "Losing a friend to hate crime, and the many LGBTQ suicides has really lit a match within me to carry my identities, not only my queer identity but all my identities, in everything I do" (Cameron, Personal Communication, November 28, 2012). His other identities closely relates to heterosexual identities that challenge the description of Stage 5 where individuals who reach 
this stage are fully immersed in the LGBTQ culture with less emphasis on identities that relates with the heterosexual identity.

\section{Conclusion}

Cass Model of Sexual Identity Formation identified stages that are apparent to the coming out process and growth to LGBTQ identified person. Every stage depicts commonality of development that can be considered valid in the eyes of individuals who are trying to understand one's sexual identity. Life experiences are unique for every individuals especially stories of coming out. However, there can be uniformity in emotions invested in each of these stories. Emotions like fear, hate, hurt, nervous, confuse, uncomfortable, affirmed, happy, secure, frustrated, confident, proud, etc. are often times evident in the process of embracing one's identity and even moving forward to discovering other layers of one's identity. The diversity of experiences varies within individuals. This means that what may apply for one may not apply for another, which defeats the assumptions that the cass model holds. The experiences of individuals are different and unique and their development is not identical with each other. The only thing that may be common among LGBTQ individuals is their awareness to the people they are attracted to. Hence, identity development is not linear for everyone. There are factors like race, ethnicity, cultural background, values, and beliefs that vary for every individual. These factors influence the experiences of every individual, which also contributes to the differences in the identity development. Consequentially, one cannot assume that progression cannot only be measured in a linear movement. Sometimes, a person chooses to remain in one phase and never progress or regress. Some may reach all the stages, but all those stages are happening at different times and not sequentially. The model was from a research in the 1970s. Society at the time has a different perspective on LGBTQ identity where it is seen as a disorder or sickness. Nowadays, society has becoming more tolerant and accepting of the LGBTQ community. It is seen as process of self-understanding and self-structuring one's identity. Furthermore, development has no limits, rather through changing time individuals are consistently learning and being challenged. Like Cameron, he believes that he already reached Stage 6: Identity Synthesis. However, he feels that he is continuously changing and growing through time even after reaching the last stage because identity itself is fluid and flexible. Lastly, identity integration through engaging one self in social activities contributes to the patterns of identity development. A study cannot restrict the explanation of an individual's progress on the constructed developmental stages, instead one has the ability to create his or her own developmental stages according to his or her processing and understanding of oneself. Additionally, the end point stage cannot be determined through research. One can construct his or her own ideal stage to attain at his or her own individual context.

As student affairs practitioners, one must be adaptable to the fluidity of gender identity development. Moreover, one must be conscious and aware of the complexities and uniqueness of one's experiences. The stages of sexual identity development are protocol to further one's research and to emphasize the need to educate the community on these changing meaning of concepts. Theories and models opened the path to improve and to review studies in order to accommodate the needs of individuals and be congruent to the society's present condition.

\section{References}

Bilodeau, B. L., \& Renn, K. A. (2005). Analysis of lgbt identity development models and implications for practice. Retrieved from http://lbgtrc.msu.edu/docs/bilodeaurenn.pdf

Cameron, C. (2012, September 27). Interview by F. A. Aglipay (Audio Tape Recording). Interview 1., San Francisco. 
Cameron, C. (2012, November 23). Interview by F. A. Aglipay (Audio Tape Recording). Interview 2., San Francisco. Cameron, C. (2012, November 28). Interview by F. A. Aglipay (Audio Tape Recording). Interview 3., San Francisco.

Cass, V. C. (1979). Homosexual identity formation: A theoretical model. Journal of Homosexuality, 4, 219-235. Retrieved from http://multicultural.usf.edu/pdf/safezone/support_identity.pdf

Degges-White, S., Rice, B., \& Myers, J. E. (2000). Revisiting Cass' theory of sexual identity formation: A study of lesbian development. Journal of Mental Health Counseling, 22(4), 318-333. Retrieved from http://www.sagepub.com/

Evans, N. J., Forney, D. S., Guido, F. M., Patton, L. D., \& Renn, K. A. (2010). Student development in college: Theory, research, and practice (2nd ed.). San Francisco: Jossey- Bass.

Rosario, M., Schrimshaw, E. W., \& Hunter, J. (2011). Predicting different patterns of sexual identity development over time among lesbian, gay, and bisexual youths: A cluster analytic approach. Am. J. Community Psychol., 266-282. Retrieved from http://www.ncbi.nlm.nih.gov/pmc/articles/PMC3192490 